Ildariya Khairullovna Valeeva: None declared., Jana Shevnina: None declared., Diana Abdulganieva: None declared.

DOI: 10.1136/annrheumdis-2021-eular.4006

\begin{tabular}{|l|l|}
\hline AB0485 & DOES THE REASON OF DISCONTINUATION OF \\
THE FIRST TNF INHIBITOR INFLUENCE THE \\
RESPONSE TO THE SECOND TNF INHIBITOR IN \\
SPONDYLARTHRITIS? PILOT STUDY FROM THE \\
MOROCCAN RBSMR REGISTRY
\end{tabular}

T. Fatima Zahrae ${ }^{1}$, T. Latifa ${ }^{2}$, H. Rkain ${ }^{2}$, I. Hmamouchi ${ }^{2}$, L. Achemlal ${ }^{2}$, I. El Bouchti ${ }^{3}$, A. Elmaghraoui ${ }^{2}$, I. Ghozlani ${ }^{4}$, H. Hassikou ${ }^{5}$, T. Harzy ${ }^{6}$, L. Ichchou ${ }^{7}$, O. Mkinsi ${ }^{8}$, R. Niamane ${ }^{9}$, R. Bahiri ${ }^{2}$, F. Allali ${ }^{2}{ }^{1}{ }^{1}$ Faculty of Medicine and Pharmacy of Tangier, Adelmalek Essaadi University, Rheumatology, Tangier, Morocco; ${ }^{2}$ Faculty of Medicine and Pharmacy of Rabat, Mohammed V University, Rheumatology, Rabat, Morocco; ${ }^{3}$ Arrazi University Hospital, Rheumatology, Marrakech, Morocco; ${ }^{4}$ University Hospital of Agadir, Rheumatology, Agadir, Morocco; ${ }^{5}$ Military Hospital Moulay Ismail, Hassan II University Hospital, Rheumatology, Meknes, Morocco; ${ }^{6}$ Hassan II University Hospital, Rheumatology, Fez, Morocco; ${ }^{7}$ Mohammed VI University Hospital, Rheumatology, Oujda, Morocco; ${ }^{8} \mathrm{Ibn}$ Rochd University Hospital, Rheumatology, Casablanca, Morocco; ${ }^{9}$ Military Hospital Avicenne, Mohammed VI University Hospital, Rheumatology, Marrakech, Morocco

Background: In rheumatoid arthritis, studies have shown that the response to a second TNF inhibitor is better if the first TNF inhibitor was stopped for a secondary failure or adverse event compared to a primary failure [1,2]. However, few studies have provided evidence regarding the response to a second TNF inhibitor based on the reason for discontinuation of the first TNF inhibitor in patients with a diagnostic of spondyloarthritis (SpA).

Objectives: To evaluate the efficacy of the 2nd TNF inhibitor in real life from a cohort of patients with SpA from the Moroccan registry of biological therapies in rheumatic diseases (RBSMR Registry), according to the reason for discontinuation of the 1st TNF inhibitor.

Methods: We have included from the RBSMR Registry any patient with a diagnosis of SpA starting a 2nd TNF inhibitor on inclusion in the registry or during the 1st year of follow-up. A descriptive study was conducted by measuring the therapeutic maintenance of the 2nd TNF inhibitor as well as the disease activity in different groups of patients according to the reason for stopping the first TNF inhibitor: stopping for ineffectiveness, side effect or non-availability of the drug. Results: Of the total 194 patients with SpA included in the RBSMR registry, 40 patients were on their 2nd TNF inhibitor at one year follow-up. The mean age of the patients was $43.6 \pm 15.1$ with a male predominance $(57.5 \%)$ and a mean of disease duration of $13.75 \pm 6.95$ years. At 1 year, treatment was maintained in $72.5 \%$ of all patients: $100 \%$ after ineffectiveness, $82 \%$ after discontinuation for side effects and $52.9 \%$ for unavailability of the first TNF inhibitor. Moderate disease activity as defined by an Ankylosing Spondylitis Disease Activity Score using ASDAS-CRP $<2.1$ was achieved at 1 year in $75 \%, 64.7 \%$ and $52.9 \%$ respectively in patients who stopped their first TNF inhibitor for side effects, ineffectiveness or unavailability of treatment. Conclusion: This pilot study gives us a small insight into the fate and efficacy of the 2nd TNF inhibitor based on the reason for discontinuation of the first. The follow-up data at 2 and 3 years will allow us to include more patients and thus be able to do a real statistical study with a comparison between the different groups. REFERENCES:

[1] Remy A, Avouac J, Gossec L, Combe B. Clinical relevance of switching to a second tumour necrosis factor- $\alpha$ inhibitor after discontinuation of a first tumour necrosis factor- $\alpha$ inhibitor in rheumatoid arthritis: a systematic literature review and meta-analysis. Clin Exp Rheumatol. 2011;29:96-103.

[2] Chatzidionysiou K, Askling J, Eriksson J, Kristensen LE, van Vollenhoven R, ARTIS group. Effectiveness of TNF inhibitor switch in RA: results from the national Swedish register. Ann Rheum Dis. 2015;74:890-6.

Disclosure of Interests: None declared.

DOI: 10.1136/annrheumdis-2021-eular.4104

\section{AB0486 ONE-YEAR DIRECT COSTS OF BIOLOGICAL THERAPY IN ANKYLOSING SPONDYLITIS AND ITS PREDICTIVE FACTORS: DATA FROM THE MOROCCAN RBSMR REGISTRY}

$\underline{\text { S. Bahloul }}{ }^{1}$, H. Rkain ${ }^{2}$, S. Fellous ${ }^{2}$, S. Ahid ${ }^{3}$, R. Abouqal ${ }^{4}$, T. Latifa $^{2}$, I. Hmamouchi ${ }^{5}$, L. Achemlal ${ }^{6}$, I. El Bouchti ${ }^{7}$, A. EL Maghraoui ${ }^{6}$, I. Ghozlani ${ }^{8}$, H. Hassikou ${ }^{9}$, T. Harzy $^{10}$, I. Linda ${ }^{11}$, O. Mkinsi' ${ }^{2}$, R. Niamane ${ }^{13}$, R. Bahiri', F. Allali'. ${ }^{1}$ El Ayachi Hospital, Rheumatology, Salé, Morocco; ${ }^{2}$ El Ayachi Hospital, Rheumatology, salé, Morocco; ${ }^{3}$ Mohamed 5 university, Pharmaco economic - pharmaco epidemology Laboratory, RABAT, Morocco; ${ }^{4}$ Mohamed 5 university, laboratory of biostatiscal clinical and epidemiological research,
RABAT, Morocco; ${ }^{5}$ Provincial hospital of temara, Rheumatology, Temara, Morocco; ${ }^{6}$ military hospital Mohamed 5, Rheumatology, RABAT, Morocco; ${ }^{7}$ Razi unvesity Hospital, Rheumatology, Marrakech, Morocco; ${ }^{8}$ university hospital, Rheumatology, agadir, Morocco; ${ }^{9}$ military hospital moulay ismail, Rheumatology, Meknes, Morocco; ${ }^{10}$ Hassan II university hospital, Rheumatology, Fes, Morocco ${ }^{11}$ Mohamed 5 university, Rheumatology, OUJDA, Morocco; ${ }^{12} \mathrm{lbn}$ Rochd university Hospital, Rheumatology, Casablanca, Morocco; ${ }^{13}$ military hospital avicenne, Rheumatology, Marrakech, Morocco

Background: NA

Objectives: To estimate the annual direct costs of biological therapies in Spondyloarthropathies $(\mathrm{SpA})$ and to establish possible factors associated with those costs.

Methods: The main data source was the Moroccan registry of biological therapies in rheumatic diseases (RBSMR). We included SpA patients with available 1-year data. Variables related to socioeconomic status, disease and biological therapy were collected. Differences in costs across groups were tested by Mann-Whitney and Kruskal-Wallis tests. Correlations analysis was performed in search of factors associated with high costs.

Results: We included $89 \mathrm{SpA}$ patients. The mean age was $40.6 \pm 13.6$ years, with male predominance $68.9 \%$. Patients received one of the following therapies: TNF-blockers $(n=79)$, Biosimilar of TNF-blockers $(n=8)$ and II17-blockers $(n=2)$. Median one-year biologic costs per patient were $9569,39 €$. The total annual of biotherapies in AS patients was $851675,98 €$.

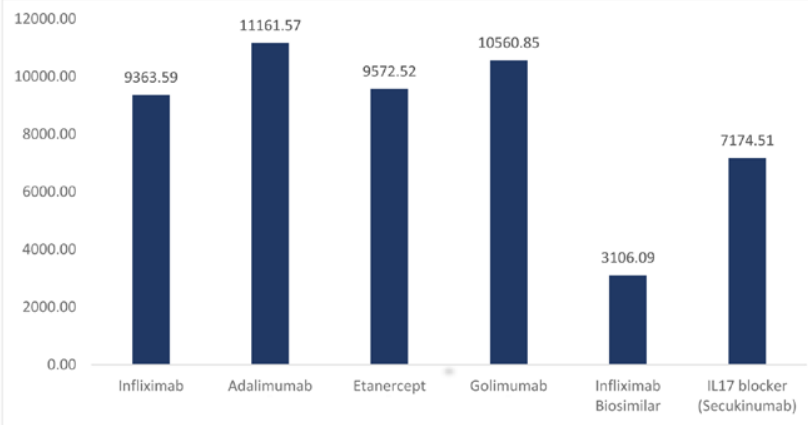

Figure 1 Annual mean drug costs per treated patient ( $€$ : Euro)

The costs are presented in Euro using an exchange rate of (1 Moroccan Dirham $=0.091$ Euro).

TNF-blockers constituted $95 \%$ of the total annual budget. Biosimilar of TNF-blockers and II1-blockers represented $3 \%$ and $2 \%$ of this overall budget, respectively. Although the costs were not significantly different in terms of gender or level of study, the insurance type significantly affected the cost estimation.

No correlation was found between the annual direct costs of biotherapies and body mass index nor with BASFI or BASDAI.

Conclusion: In Morocco, a developing country, the annual direct costs of biological therapies are high in AS patients. Our results may contribute to the development of strategies for better governance of these costs.

Disclosure of Interests: None declared.

DOI: 10.1136/annrheumdis-2021-eular.4117

\section{Spondyloarthritis - clinical aspects (other than treatment)}

\begin{tabular}{|l}
\hline AB0487 \\
HEPSIDINE LEVEL IN PATIENTS WITH ANKYLOSING \\
SPONDYLITIS, RELATIONSHIP WITH HEMOPOESIS \\
AND FERROKINETICS
\end{tabular}

O. Zviahina ${ }^{1}$, S. Shevchuk ${ }^{1} .{ }^{1}$ National Pirogov Memorial Medical University, Vinnytsya, Internal Medicine Chair \# 2, Vinnytsya, Ukraine

Background: Hypoferimia, as a manifestation of systemic inflammation, is quite common in patients with ankylosing spondylitis (AS). Anemic syndrome can be represented by anemia of chronic disease (ACD), iron deficiency anemia (IDA) and their combination. Its frequency of occurrences ranges from 18.5 to $45.8 \%$. The discovery of the hormone hepcidin in 2001 changed the perception of iron metabolism disorders and demonstrated its association with the inflammatory component. Over the last decade, scientific databases have accumulated a lot 
of information about hepcidin and its role in the development of anemia and the response to inflammation. However, in the context of the AS, such data are contradictory and therefore need further study.

Objectives: To determine the level of hepcidin in patients with ankylosing spondylitis and to assess its relationship with hematopoiesis and ferrokinetics. Methods: The hepcidin levels of 76 patients with ankylosing spondylitis (13 women and 63 men with a mean age of $43.67 \pm 0.97$ years). The diagnosis of AS was made according to the New York modified criteria of 1984. All patients were divided into three groups: without anemia $(n=47)$, with anemia $(n=29)$ and the control group, representative by age and sex $(n=26)$. According to the percentile analysis, all patients were divided into a group with an optimal $<25 \mathrm{ng} / \mathrm{ml}$, extremely high $-25-35 \mathrm{ng} / \mathrm{ml}$ and a high level of hepcidin $>35 \mathrm{ng} / \mathrm{ml}$. In addition to hepcidin, hematopoiesis and ferrokinetic parameters were measured in each patient: hemoglobin $(\mathrm{Hb})$, erythrocyte, MCV, serum iron, total serum iron-binding capacity (TIBC), serum ferritin, transferrin saturation (TS). Statistical processing of the obtained results was performed with the use of statistical software package "Microsoft Office Excel 2007".

Results: When conducting a percentile comparison in $95 \%$ of people in the control group, the level of hepcidin was in the range of $17.97-38.8 \mathrm{ng} / \mathrm{ml}\left(\mathrm{P}_{5}-\mathrm{P}_{95}\right)$, and in patients with AS in $95 \%-14.62-87.38 \mathrm{ng} / \mathrm{ml}$. At $P_{95}$, the level of hepcidin in patients with $\mathrm{AS}$ was 2.3 times higher than in $\mathrm{P}_{95}$ control group. Comparing the mean values of hepcidin, a significant difference was found between the group of patients without anemia, where it was $36.08 \pm 2.57 \mathrm{ng} / \mathrm{ml}$ and the group of patients with anemia, where the level of hepcidin was $51.77 \pm 4.62 \mathrm{ng} / \mathrm{ml}$. The lowest level of hepcidin was in patients with IDA $(35.8 \pm 7.50 \mathrm{ng} / \mathrm{ml})$, and the highest $(62.78 \pm 5.94 \mathrm{ng} / \mathrm{ml})$ - among patients with ACD. The group of patients with ACD and iron deficiency, according to the levels of hepcidin $(48.53 \pm 9.50 \mathrm{ng} / \mathrm{ml})$ took an intermediate place.

In terms of hematopoiesis and ferrokinetics, the level of hemoglobin and erythrocytes did not differ significantly between the groups of optimal, extremely high and high levels of hepcidin. According to the levels of serum iron, TS and ferritin in the group of patients with anemia, a significant association with hepcidin was established (with increasing levels of hepcidin, the values of serum iron, TS and ferritin also increased). In contrast,sTfR levels were the highest in the group with optimal hepcidin levels $(6.02 \pm 0.71 \mathrm{mg} / \mathrm{l})$ and decreased to $4.88 \pm 0.64 \mathrm{mg} / \mathrm{l}$ in the group with high hepcidin levels. Such changes in hematopoiesis and ferrokinetics were explained by the accumulation of mostly people with symptoms of ACD in the group with high levels of hepcidin, and the group with optimal levels of hepcidin consisted mainly of patients with IDA.

Conclusion: Patients with AS have elevated serum hepcidin levels, it is higher in individuals with anemic syndrome than in patients without anemia and is associated with serum iron, TS and ferritin levels.

Disclosure of Interests: None declared.

DOI: 10.1136/annrheumdis-2021-eular.382

\section{AB0488 $\quad$ SPONDYLOARTHRITIS DISEASE BURDEN AS PERCEIVED BY PATIENTS: BASELINE PATIENT- REPORTED OUTCOME DATA FROM THE ITALIAN PROSPECTIVE SIRENA STUDY}

R. Foti ${ }^{1}$, G. Cardinale ${ }^{2}$, L. Costa ${ }^{3}$, F. Franceschini ${ }^{4}$, F. Ciccia $^{5}$, A. Marchesoni ${ }^{6}$, G. Guggino ${ }^{7}$, M. Rossini ${ }^{8}$, E. Lubrano DI Scorpaniello ${ }^{9}$, B. Frediani ${ }^{10}$, M. S. Chimenti ${ }^{11}$, G. Bianchi ${ }^{12}$, G. Galfo ${ }^{13}$, S. Marelli ${ }^{14}$, E. Favalli ${ }^{15}$ on behalf of SIRENA Study Group. ${ }^{1}$ Azienda Ospedaliero Universitaria Policlinico Vittorio Emanuele, U.O. Reumatologia, Catania, Italy; ${ }^{2}$ Distretto nr. 1 ULSS6 Euganea, U.O.S. Reumatologia, Padova, Italy; ${ }^{3}$ Università degli Studi di Napoli Federico II, U.O.C. Reumatologia, Dipartimento di Medicina Clinica e Chirurgia, Naples, Italy; ${ }^{4}$ ASST Spedali Civili, Università di Brescia, U.O.C. Reumatologia and Immunologia Clinica, Dept of Clinical and Experimental Sciences, Brescia, Italy; ${ }^{5}$ Università della Campania L Vanvitelli, U.O.C. Reumatologia, Dipartimento di Medicina di Precisione, Naples, Italy; ${ }^{6}$ ASST Centro Specialistico Ortopedico Traumatologico Gaetano Pini - CTO, S.C. Day Hospital di Reumatologia, Milan, Italy; ${ }^{7} \mathrm{AOU}$ Policlinico Paolo Giaccone e Università degli Studi di Palermo, U.O. Reumatologia, Palermo, Italy; ${ }^{8}$ Azienda Ospedaliera Universitaria Integrata, U.O.C. Reumatologia, Verona, Italy; ${ }^{9}$ Università degli Studi del Molise, U.O.S. V.D. Reumatologia, Dipartimento di Medicina e Scienze della Salute, Campobasso, Italy; ${ }^{10}$ Azienda Ospedaliera Universitaria Senese, U.O.C. Reumatologia, Siena, Italy; ${ }^{11}$ Università di Roma Tor Vergata, Reumatologia, Allergologia e Immunologia Clinica, Dipartimento di Medicina dei Sistemi, Rome, Italy; ${ }^{12}$ ASL3 Genova, S.C. Reumatologia, Genova, Italy; ${ }^{13}$ Azienda Provinciale Sanitaria di Ragusa, U.O. Reumatologia e Medicina Generale, Lungodegenza Ospedale Busacca, Scicli (RG), Italy; ${ }^{14}$ Janssen, Medical Affairs Department, Immunology, Cologno Monzese (MI), Italy; ${ }^{15}$ ASST Centro Specialistico Ortopedico Traumatologico Gaetano Pini - CTO, S.C. Reumatologia, Milan, Italy

Background: Previous studies have compared Patient-Reported Outcomes (PROs) in Spondyloarthritis (SpA); a recent one has found similarity in Psoriatic Arthritis (PsA) and axial patients ${ }^{1}$.
Objectives: To describe PROs at SpA diagnosis (new or confirmed), by type of SpA and by gender.

Methods: SIRENA is an Italian, prospective Registry of SpA patients diagnosed according to ASAS criteria and naïve to any DMARDs. At inclusion, patients were classified as predominant axial (AxSpA) or mainly peripheral (pSpA). PROs showed in the Table 1 were collected and analysed descriptively.

Table 1. PhGA and PROs at diagnosis*

\begin{tabular}{|c|c|c|c|c|c|c|}
\hline & $\mathrm{AxSpA}^{*}$ & & & pSpA & & \\
\hline & $\begin{array}{l}\text { All } \\
(n=123)\end{array}$ & $\begin{array}{l}\text { Women } \\
(n=64)\end{array}$ & $\begin{array}{l}\text { Men } \\
(n=58)\end{array}$ & $\begin{array}{l}\text { All } \\
(n=227)\end{array}$ & $\begin{array}{l}\text { Women } \\
(n=109)\end{array}$ & $\begin{array}{l}\text { Men } \\
(n=118)\end{array}$ \\
\hline PhGA, $n$ & 115 & 60 & 54 & 222 & 105 & 117 \\
\hline mean (SD) & $50.2(28.6)$ & $54.8(26.7)$ & $45.0(30.1)$ & $45.4(25.9)$ & $49.9(25.6)$ & $\begin{array}{l}41.3 \\
(25.6)\end{array}$ \\
\hline median $(\min , \max )$ & $52.0(0-100)$ & $62.0(0-100)$ & $\begin{array}{l}43.5 \\
(0-100)\end{array}$ & $48.5(0-100)$ & $\begin{array}{l}50.0 \\
(1.0-100)\end{array}$ & $\begin{array}{l}40.0 \\
(0-95.0)\end{array}$ \\
\hline $\begin{array}{l}\text { PtGA, } \mathbf{n} \\
\text { mean (SD) }\end{array}$ & $\begin{array}{l}112 \\
56.4(27.8)\end{array}$ & $\begin{array}{l}59 \\
61.5(25.8)\end{array}$ & $\begin{array}{l}52 \\
50.3(29.2)\end{array}$ & $\begin{array}{l}209 \\
50.3(26.2)\end{array}$ & $\begin{array}{l}102 \\
56.4(23.1)\end{array}$ & $\begin{array}{l}107 \\
44.5\end{array}$ \\
\hline & & & & & & $(27.7)$ \\
\hline median (min, max) & $63.0(0-100)$ & $\begin{array}{l}70.0 \\
(2.0-100)\end{array}$ & $\begin{array}{l}50.0 \\
(0-100)\end{array}$ & $50.0(0-100)$ & $\begin{array}{l}58.5 \\
(7.0-100)\end{array}$ & $\begin{array}{l}47.0 \\
(0-100)\end{array}$ \\
\hline $\begin{array}{l}\text { Pain VAS score, } \mathbf{n} \\
\text { mean (SD) }\end{array}$ & $\begin{array}{l}113 \\
56.7(28.3)\end{array}$ & $\begin{array}{l}60 \\
61.1(26.6)\end{array}$ & $\begin{array}{l}52 \\
50.6(29.1)\end{array}$ & $\begin{array}{l}207 \\
51.9(26.8)\end{array}$ & $\begin{array}{l}101 \\
57.4(25.3)\end{array}$ & $\begin{array}{l}106 \\
46.8\end{array}$ \\
\hline median (min, $\max )$ & $60.0(0-100)$ & $\begin{array}{l}69.5 \\
(2.0-100)\end{array}$ & $\begin{array}{l}50.0 \\
(0-100) \\
52\end{array}$ & $53.0(0-100)$ & $61.0(0-100)$ & $\begin{array}{l}(27.3) \\
48.5 \\
(0-100) \\
108\end{array}$ \\
\hline $\begin{array}{l}\text { leep VAS S } \\
\text { mean (SD) }\end{array}$ & $55.3(29.3)$ & $57.4(29.5)$ & $52.3(29.2)$ & $44.0(30.1)$ & $50.4(29.8)$ & $\begin{array}{l}108 \\
37.9 \\
(29.2)\end{array}$ \\
\hline median $(\min , \max )$ & $59.0(0-100)$ & $61.5(0-100)$ & $\begin{array}{l}53.0 \\
(0-100)\end{array}$ & $44.0(0-100)$ & $53.0(0-100)$ & $\begin{array}{l}34.0 \\
(0-100)\end{array}$ \\
\hline BASFI, n & 110 & 58 & 51 & 133 & 65 & 68 \\
\hline mean (SD) & $4.6(2.8)$ & $5.2(2.6)$ & $3.9(2.8)$ & $3.5(2.6)$ & $4.0(2.6)$ & $\begin{array}{l}3.1 \\
(2.4)\end{array}$ \\
\hline median (min, max) & $5.1(0-9.7)$ & $5.8(0-9.4)$ & $3.6(0-9.6)$ & $2.9(0-10.0)$ & $3.9(0-10.0)$ & $\begin{array}{l}2.45 \\
(0-8.9)\end{array}$ \\
\hline ASDAI, n & 112 & 59 & 52 & 139 & 70 & 69 \\
\hline mean (SD) & 5.2( & 5.8 & $4.5(2.3)$ & $5.2(2.3)$ & $5.8(2.1)$ & $\begin{array}{l}4.6 \\
(2.3)\end{array}$ \\
\hline median (min, max) & $5.5(0-9.3)$ & $6.2(0-9.3)$ & $\begin{array}{l}4.5 \\
(0.3-9.2)\end{array}$ & $\begin{array}{l}5.5 \\
(0.2-10.0)\end{array}$ & $\begin{array}{l}6.1 \\
(1.0-10.0)\end{array}$ & $\begin{array}{l}4.8 \\
(0.2-9.2)\end{array}$ \\
\hline HAQ-DI score, $n$ & 109 & 58 & 50 & 203 & 99 & 104 \\
\hline mean (SD) & $0.9(0.7)$ & $1.1(0.7)$ & $0.6(0.6)$ & $0.7(0.7)$ & $0.9(0.7)$ & $\begin{array}{l}0.6 \\
(0.6)\end{array}$ \\
\hline median (min, $\max$ ) & $0.8(0.0-2.5)$ & $1.1(0-2.5)$ & $0.5(0-2.3)$ & $0.6(0.0-2.8)$ & $0.8(0-2.8)$ & $\begin{array}{l}0.4 \\
(0-2.6)\end{array}$ \\
\hline \multicolumn{7}{|l|}{ WPAI } \\
\hline $\begin{array}{c}\% \text { work time } \\
\text { missed, } n\end{array}$ & 49 & 19 & 30 & 107 & 45 & 62 \\
\hline mean (SD) & $7.3(21.4)$ & $4.2(9.5)$ & $9.2(26.3)$ & $8.8(24.7)$ & $8.6(25.6)$ & $\begin{array}{l}8.9 \\
(24.3)\end{array}$ \\
\hline median (min, max) & $0(0-100)$ & $0(0-35.1)$ & $0(0-100)$ & $0(0-100)$ & $0(0-100)$ & $\begin{array}{l}0 \\
(0-100)\end{array}$ \\
\hline $\begin{array}{l}\text { \% impairment at } \\
\text { work, } n\end{array}$ & 67 & 33 & 34 & 134 & 61 & 73 \\
\hline mean (SD) & $48.2(31.9)$ & $58.5(26.6)$ & $38.2(33.7)$ & 39.7 (31.4) & $45.4(30.9)$ & $\begin{array}{l}34.9 \\
(31.2)\end{array}$ \\
\hline median (min, max) & $50.0(0-100)$ & $60.0(0-100)$ & $\begin{array}{l}25.0 \\
(0-100)\end{array}$ & $40.0(0-100)$ & $50.0(0-100)$ & $\begin{array}{l}30.0 \\
(0-100)\end{array}$ \\
\hline $\begin{array}{l}\text { \% overall work } \\
\quad \text { impairment, } n\end{array}$ & 48 & 19 & 29 & 106 & 45 & 61 \\
\hline mean (SD) & $44.1(33.0)$ & $52.4(27.9)$ & 38.7 (35.3) & $40.1(33.0)$ & $45.1(33.1)$ & $\begin{array}{l}36.4 \\
(32.7)\end{array}$ \\
\hline median (min, max) & $45.0(0-100)$ & $60.0(0-100)$ & $\begin{array}{l}20.0 \\
(0-100)\end{array}$ & $40.0(0-100)$ & $50.0(0-100)$ & $\begin{array}{l}30.0 \\
(0-100)\end{array}$ \\
\hline $\begin{array}{l}\% \text { activity impair- } \\
\text { ment, } n\end{array}$ & 100 & 53 & 46 & 183 & 93 & 90 \\
\hline mean (SD) & $56.7(28.6)$ & $63.4(23.9)$ & $48.0(31.0)$ & $48.5(30.3)$ & $55.3(28.7)$ & $\begin{array}{l}41.4 \\
(30.4)\end{array}$ \\
\hline median (min, max) & $60.0(0-100)$ & $70.0(0-100)$ & $\begin{array}{l}50.0 \\
(0-100)\end{array}$ & $50.0(0-100)$ & $60.0(0-100)$ & $\begin{array}{l}40.0 \\
(0-100)\end{array}$ \\
\hline
\end{tabular}

* The sum does not add up to the total because of some missing values.

Results: From 23 sites, $123 \mathrm{AxSpA}$ and $227 \mathrm{pSpA}$ patients were analysed. Diagnosis was new in $58 \%$ of AxSpA and $77 \%$ of pSpA. $85.5 \%$ of the pSpA had PsA, while in AxSpA the most frequent type was Ankylosing Spondylitis (48.8\%). Time from symptom onset to diagnosis was higher in AxSpA than in pSpA (median 36 vs 24 months, respectively). At inclusion, composite disease activity measures showed high disease activity for AxSpA (mean ASDASCRP 3.1) and moderate disease activity for pSpA (mean DAS28 3.6; mean DAPSA 22.5). AxSpA patients had numerically worse values than $p S p A$ in all the PROs collected, except for BASDAI score that was similar (mean 5.2). For both AxSpA and pSpA, all PROs were worse in women than men, except 